\title{
O Pibid e a licenciatura: veredas de uma mesma formação ${ }^{12} 3$
}

\section{Pibid and curricular teacher education: paths of a same formation}

\author{
Camila Itikawa Gimenes ${ }^{(i)}$
}

(i) Rede Municipal de Educação de São Paulo - SME-SP, São Paulo, SP, Brasil. https://orcid.org/00000002-7130-4517, cigimenes@gmail.com.

\begin{abstract}
Resumo
Este trabalho é resultado de pesquisa que teve como objetivo compreender o modo de constituição e funcionamento do Programa Institucional de Bolsas de Iniciação à Docência (Pibid), em especial a formação de futuros professores promovida em quatro subprojetos do programa vinculados a licenciaturas de ciências, ciências biológicas, física e química de uma universidade pública, e discutir as contribuições, contradições e limites do programa para a formação de professores e para o currículo da licenciatura, enfocando o estágio supervisionado, locus formal de formação de todos os futuros professores. Os sujeitos entrevistados destacam a potencialidade do trabalho conjunto entre escola e universidade para a formação de professores, em que o encontro pedagogicamente guiado entre pessoas de diferentes contextos é capaz de produzir importantes experiências formativas. Todavia, não obstante o Pibid seja reconhecido por seus aspectos positivos, tal construção é possível sobretudo com a caracterização negativa dos cursos de formação inicial de professores.

Palavras-chave: formação de professores, estágio, Pibid, práxis
\end{abstract}

1 Editor responsável: Pedro da Cunha Pinto Neto, pedrocpn@unicamp.br

2 Normalização, preparação e revisão textual: Luan Maitan - revisao@tikinet.com.br

3 Apoio: Fundação de Amparo à Pesquisa do Estado de São Paulo (FAPESP), processo no 2012/08428-7. 


\title{
pro.posıções \\ $e$-ISSN 1980-6248
}

http://dx.doi.org/10.1590/1980-6248-2018-0096

\begin{abstract}
The purpose of this research is to understand the constitution and functioning of Institutional Program of Initiatives for Teaching (Pibid, in Portuguese), in particular, the education of future teachers promoted in four subprojects of this Program linked to Science, Biology, Chemistry and Physics of a public university and discuss the contributions, contradictions and limits of the Program for teacher education and for its curriculum, specially for supervised internship, a formal locus of education for all future teachers. The subjects interviewed bighlight the potential of the joint work between school and university for the formation of teachers, in which the pedagogically guided encounter between people from different contexts is capable of producing important formative experiences. However, despite the fact that the Pibid is recognized for its positive aspects, such construction is possible with the negative characterization of initial teacher education courses.
\end{abstract}

Keywords: teacher education, supervised internship, Pibid, praxis

\section{Introdução}

O Programa Institucional de Bolsas de Iniciação à Docência (Pibid) possibilita aos seus participantes o cruzamento de meios que historicamente estão isolados na formação inicial de professores, como a emergência de espaços de interlocuções coletivas entre escola e universidade, a produção de práticas interinstitucionais e financiamento que favorece a construção desses espaços. Também contribui para o interesse em pesquisar esse programa o entusiasmo demonstrado pelos participantes com quem pudemos conviver. Assim, esse programa possui a potencialidade de apontar empiricamente elementos para discutir a formação docente. É diante desse potencial que se dá a escolha pelo Pibid como objeto de pesquisa de tese de doutoramento, da qual deriva este artigo.

Nosso objetivo é compreender o papel do Pibid na formação de futuros professores promovido em quatro subprojetos vinculados a licenciaturas da área das ciências da natureza de uma universidade pública, buscando apreender elementos da realidade para a discussão sobre contribuições, contradições e limites do programa para a formação de professores e para o currículo da licenciatura, em especial o estágio supervisionado, locus formal de formação de todos os futuros professores. Os recursos metodológicos de análise de documentos legais e institucionais, e entrevista semiestruturada foram utilizados para a produção dos dados desta pesquisa. São questões orientadoras da pesquisa: Quais as relações formativas tecidas entre 


\section{pro.posıções \\ $e$-ISSN 1980-6248}

http://dx.doi.org/10.1590/1980-6248-2018-0096

Pibid e os cursos de licenciatura de ciências da natureza investigados? Qual sua relação com o estágio, componente curricular obrigatório? Qual a concepção de formação de professores presente nesse programa? Quais mediações entre teoria e prática são privilegiadas nesses subprojetos? Quais mediações entre universidade e escola são privilegiadas nesses subprojetos? A partir de que atividades essas mediações são estruturadas e realizadas?

Importante ressaltar, ainda, que adotamos como recorte temporal para a realização dessa pesquisa o período entre 2007 (ano de homologação do programa) até 2014 (ano de finalização do trabalho de campo), ou seja, investigamos o período de implementação e ampliação do programa. Mais pesquisas são necessárias sobre o período subsequente de contingenciamento e cortes de gastos até sua reestruturação em início de 2018.

\section{Práxis e formação docente}

A articulação entre teoria e prática é um debate recorrente no campo da formação de professores. Schmied-Kowarzik (1988) considera, inclusive, a relação entre teoria e prática como a mais fundamental da pedagogia. Seja o professor entendido numa perspectiva tecnicista, prático-utilitária ou crítica, o espaço ocupado pela teoria e pela prática é constitutivo da estrutura dos cursos de formação. Essa relação é sempre conflitiva, originando diferentes propostas de solução e frequentemente contrárias.

Para discutir a relação entre teoria e prática, tomamos como ponto de partida o fato de que há diferenças constitutivas entre elas. A primeira transforma nossa consciência dos fatos, nossas ideias sobre as coisas, mas não as próprias coisas; a segunda pressupõe uma ação efetiva sobre o mundo, tendo como resultado a sua transformação real. Entretanto, trata-se de diferenças que se articulam dialeticamente na relação entre teoria e prática, e apenas no interior dessa relação podem existir.

A distinção entre teoria e prática é uma relação necessária e falsa. É necessária, pois determina fenômenos distintos, e sua caracterização nos ajuda a compreender a realidade social e a resolver certos problemas, ainda que nunca seja uma distinção absoluta. Mas também é falsa, pois, se hipostasiada, teoria e prática não existem como momentos plenamente separados, só existem em relação: a teoria carrega em si uma prática, e esta é a realização de uma intencionalidade humana, portanto, contém em si uma teoria. 


\section{pro-posıções \\ $e$-ISSN 1980-6248}

http://dx.doi.org/10.1590/1980-6248-2018-0096

Teoria e prática, portanto, se relacionam dialeticamente constituindo a práxis. Vázquez $^{4}$ (2011) contribui para essa discussão, pois assume, e o faz de modo excepcionalmente preciso, a missão de conceituar práxis, atividade teórica e atividade prática. A partir dessa compreensão e a ela articulada, discutiremos a possibilidade de construção de processos que promovam a práxis na formação de professores.

A práxis é um tipo específico de atividade, que, como atitude humana transformadora da natureza e da sociedade, é atividade teórica e prática; "prática, na medida em que a teoria, como guia da ação, molda a atividade do homem, particularmente a atividade revolucionária; teórica, na medida em que essa relação é consciente” (Vázquez, 2011, p. 117).

Um elemento central para a distinção da práxis diz respeito a sua adequação a fins. Ou seja, a práxis é sempre carregada de intencionalidade, de um projeto de futuro com base nas determinações do passado; ela inicia-se com um resultado ideal e termina com um resultado real. O primeiro é fruto da intervenção da consciência como antecipação do resultado real que se almeja obter. Isso não significa que o resultado obtido seja necessariamente uma imitação real de um modelo ideal preexistente. Pelo contrário, pode assemelhar-se um pouco ou mesmo nada, pois sofre mudanças, às vezes radicais, no processo de sua realização. Essa abertura ao indeterminado entre idealização e realização é justamente o que garante que a práxis constitua um processo não teleológico e passível de transformação da realidade social.

A adequação a fins pressupõe o conhecimento teórico, que se caracteriza como uma modalidade peculiar de conhecimento; é aquele produzido através do processo de reprodução, no plano do pensamento, do movimento real do objeto precisamente para apreender não a aparência ou a forma dada ao objeto, mas sua essência, sua estrutura e sua dinâmica. É importante ressaltar que há outras formas de se conhecer a realidade como, por exemplo, a arte, o conhecimento prático da vida cotidiana, o conhecimento mágico-religioso. Entretanto, a teoria se distingue dessas modalidades e tem especificidades que se relacionam com o compromisso em conhecer o objeto como ele é em si mesmo, na sua existência real e efetiva, independentemente dos desejos, das aspirações e das representações do pesquisador, assim como o compromisso com o critério de verificação de sua verdade, instância que é a prática social e histórica (Netto, 2011).

4 Filósofo espanhol que com o exílio político no México na época da guerra civil espanhola adota o país latinoamericano como lar. Vázquez apresentou como tese de doutorado em 1961, a qual considera sua obra maior, Filosofia da práxis, publicada em forma de livro com título homônimo em 1967. 


\section{pro-posıções \\ $e$-ISSN 1980-6248}

http://dx.doi.org/10.1590/1980-6248-2018-0096

A prática, por sua vez, é fundamento, finalidade e critério de verdade da teoria. A primazia da prática sobre a teoria, longe de implicar contradição ou dualidade, pressupõe íntima vinculação a ela (Vázquez, 2011). Em outras palavras, o que queremos demonstrar com a primazia da prática é o fato de não ser a consciência que determina a vida, mas a vida que determina a consciência.

$\mathrm{Na}$ atividade prática, o sujeito age sobre uma matéria que existe independentemente de sua consciência, e das diferentes operações ou manipulações exigidas para sua transformação, que ultrapassa os limites do interesse individual e do utilitarismo, para além dos interesses subjetivos. Prática designa, em sentido amplo, a atividade transformadora do mundo (entendendo-o como mundo natural e social, como natureza e sociedade); é, portanto, real, objetiva ou material. Ela não ocorre de modo imediato e sem intermediação, requer uma decisão consciente, acaba sempre incluindo elementos teóricos (Vázquez, 2011).

Entretanto, para a consciência comum, a atividade prática reduz-se a um simples dado que não requer explicação, reduz-se a uma única dimensão, a do prático-utilitário, é individual e autossuficiente. O mundo da prática, do comportamento prático, é o mundo em que nos desenvolvemos a cada momento: o mundo de cada dia, o mundo cotidiano, uma relação ativa em que somos sujeitos ou agentes de certos atos que produzem efeitos, que têm resultados concretos, tangíveis, que denominamos justamente práticos (Vázquez, 2011).

No contexto do pragmático $^{5}$, a atividade teórica - imprática e improdutiva por excelência - se torna estranha, não se reconhece nela nada que seja de interesse imediato ou de utilidade. Por isso, o homem comum menospreza a teoria, reiterando mais uma vez a separação abstrata entre teoria e prática. Tal ideologia impregna o senso comum, não por acaso, possibilitando a crença em ideias prontas, automatização de respostas, repetição de que as coisas são como são e o mundo não poderia ser diferente.

Com essa interpretação restrita de teoria, a docência passa a ser entendida a partir do prisma da prática, defendendo-se que a produção intelectual e os avanços teóricos têm afetado muito pouco a prática dos professores e, quando chegam à escola e à sala de aula, sua apropriação é precária ou equivocada, uma vez que os professores não compreenderiam o

${ }^{5}$ Utilizamos pragmático na perspectiva apresentada por Vázquez (2011), para quem o senso comum e a doutrina filosófica de ponto de vista do pragmatismo concebem a prática num sentido estritamente utilitário, contrapondo-a à teoria. Sobretudo, a concepção de verdade para a perspectiva do pragmatismo deduz que o verdadeiro se reduz ao útil. Desse modo, a verdade "é posta em relação com nossas crenças e, além disso, com as crenças que nos são mais vantajosas" (idem, p. 243). 


\section{pro.posıções \\ $e$-ISSN 1980-6248}

http://dx.doi.org/10.1590/1980-6248-2018-0096

conhecimento abstrato e o discurso complexo produzido e divulgado pela academia. Portanto, através dessa perspectiva, justifica-se um esvaziamento teórico nos cursos de formação docente, pois se defende que esses cursos pouco contribuem para a prática profissional, uma vez que são muito teóricos e se relacionam insuficientemente com a realidade que o futuro professor encontrará na escola.

Em oposição a essa estreita concepção de formação e de docência, entendemos o movimento de formação docente enquanto processo de autonomia e dependência entre teoria e prática. A teoria que se reivindica engloba tanto os saberes específicos da área de formação, o conhecimento produzido pela pesquisa em educação e nas ciências humanas e sociais, como também aqueles produzidos nas escolas em contexto.

Assim, a teoria se realiza enquanto dimensão da práxis educativa quando revela ao educador a realidade da prática e se torna orientação para sua práxis. "Ela [a teoria] precisa, em primeiro lugar, revelar analiticamente de modo crítico as contradições sociais, os momentos da alienação na práxis educacional e de socialização anteriores, para desta maneira criar a précondição teoricamente consciente para uma revolução prática desta alienação" (SchmiedKowarzik, 1988, p. 133).

Para tanto, o curso deve tomar a realidade objetiva como ponto de partida e critério de verdade da teoria que constitui seu projeto político-pedagógico e sua estrutura curricular, assim como possibilitar experiências de aproximação e inserção na realidade escolar e na comunidade em que se situa, sendo aí o estágio constituído como o eixo estruturante do processo formativo, de modo que a licenciatura realize-se como formação na e pela práxis. A natureza pedagógica dessa concepção de formação docente vincula-se constitutivamente a objetivos educativos de formação humana, que se relaciona com a inserção crítica no mundo e com a superação das desigualdades sociais e, no limite, a superação do capitalismo.

\section{Estágio e formação docente}

O estágio curricular é compreendido como eixo privilegiado da formação inicial de professores, sendo ele entendido como práxis de professores formadores e futuros professores em formação, componente curricular e campo de conhecimentos pedagógicos. 


\section{pro.posıções \\ $e$-ISSN 1980-6248}

http://dx.doi.org/10.1590/1980-6248-2018-0096

Assim compreendido, o estágio é o coração das licenciaturas, estrutura que conforma tanto teórica como praticamente esses cursos de formação.

As diferentes concepções de formação de professores que tomam como eixo estruturante a atividade teórica dissociada da prática, correspondendo à perspectiva da racionalidade técnica; a atividade prática dissociada da teoria, à perspectiva prático-utilitária; e a práxis, à perspectiva humanizadora e emancipatória coexistem e disputam o campo epistemológico, político e prático da formação de professores. A cada uma dessas perspectivas se articula uma compreensão de estágio. Se por um lado há consenso quanto à necessidade do estágio nos cursos de licenciatura nas três concepções, por outro, há disputas em relação ao seu modo de realização e fundamento. $\mathrm{Na}$ confluência de elementos teóricos e práticos, o estágio pode compreender as categorias de estágio burocrático, prático-utilitário ou práxis, respectivamente.

Tanto na concepção de estágio burocrática quanto na prático-utilitária, a relação entre escola e universidade é compreendida de modo instrumental e hierárquico. Assim também é configurada a relação entre teoria e prática, entendendo a universidade como lugar da teoria e a escola como lugar da prática, reforçando a ilusão de que seria possível existir teoria sem prática e prática sem teoria.

O estágio na formação de professores tem, muitas vezes, ocupado um lugar burocrático ${ }^{6}$. Nessa estrutura, ele é transformado em "estágio à distância" ao final do curso, atestado burocraticamente, dando margem a burlas. Essa concepção de que o futuro professor vai à escola e apenas observa, acoberta a ideia do estágio como imitação de modelos. Nele, como criticam Pimenta e Lima (2004), o futuro professor observa e posteriormente reproduz essa prática modelar. Dito de outra forma, há uma ciência que prescreve como agir, e o professor corporifica essa ciência tal e qual, independentemente do contexto em que sua atividade docente está inserida, perspectiva também chamada de racionalidade técnica (Contreras, 2002).

Dessa forma, o trabalho realizado na universidade e na escola estão desconectados, sendo que a escola ocupa um lugar de menor prestígio social, e também nos cursos de formação é assim entendida. Há aqui uma supervalorização dos aspectos acadêmicos ditos

\footnotetext{
6 Ainda que muitos sejam os relatos de práticas formativas que superam essa precariedade e, portanto, seja impossível uma generalização, são recorrentes as críticas ao estágio nessa perspectiva.
} 


\section{pro.posıções \\ $e$-ISSN 1980-6248}

http://dx.doi.org/10.1590/1980-6248-2018-0096

teóricos. Entretanto, pela impossibilidade de a teoria existir desconectada da prática, esses saberes não podem ser teóricos, são, na verdade, saberes disciplinares de cursos de formação, que frequentemente estão desvinculados do campo de atuação profissional dos futuros professores (Pimenta \& Lima, 2004).

A concepção do estágio como um processo formativo prático-utilitário vem ganhando força nas pesquisas e nas políticas públicas, impulsionada por uma visão utilitarista da formação de professores, em que a centralidade da qualidade da educação recai individualmente sobre o professor. O desenvolvimento dessa concepção de docência se dá a partir da crítica ao modelo de racionalidade técnica, uma vez que os cursos universitários seriam muito teóricos. De maneira dissociada e assimetricamente consideradas (pois a teoria é até mesmo vista como prejudicial e, quando presente, está a serviço da prática, ou seja, sem problematizá-la, perdendo seu potencial crítico de compreender a realidade e de apontar para novas perspectivas), teoria e prática somam-se desigualmente na formação de professores. Assim, a escola é considerada como um lugar de intervenção pelo futuro professor, mas essa intervenção é, muitas vezes, precariamente planejada, uma vez que a profissão docente é considerada uma atividade que requer pouco ou nenhum preparo, defendendo um menor período de formação teórica e um maior período de formação na prática.

A concepção de estágio como práxis, entendido como componente curricular e eixo central dos cursos de formação de professores, é parte integrante do curso em sua totalidade, participando do processo formativo desde seu início. Sua finalidade é "integrar o processo de formação do aluno, futuro profissional, de modo a considerar o campo de atuação como objeto de análise, de investigação e de intervenção crítica, a partir dos nexos com as disciplinas do curso" (Pimenta \& Lima, 2004, p. 24). Desse modo, pretende-se superar o distanciamento entre a formação de professores no ensino superior e o campo de atuação do profissional docente como tema e objeto de formação. Portanto, o estágio é locus privilegiado de mediação entre a universidade e a escola.

Defendemos este componente curricular como espaço de aprendizagem da profissão docente e de construção da identidade profissional, que permeia as outras disciplinas da formação, no projeto pedagógico dos cursos de formação, mas é o lócus da sistematização da pesquisa sobre a prática, no papel de realizar a síntese e a reflexão das vivências efetivadas (Lima, 2008, p. 204). 


\section{pro.posıções \\ $e$-ISSN 1980-6248}

A essência do estágio e sua relação com o curso de licenciatura é explicitada na citação de Lima (2008), e destacamos a dimensão de sua incompletude, portanto, é um eterno processo de formar-se, humanizar-se.

\section{Pibid: história e concepção}

O Programa Institucional de Bolsas de Iniciação à Docência é uma das políticas, provavelmente a mais exitosa, que se volta para a formação docente promulgada a partir dos anos 2000, período marcado pela publicação de dezenas de políticas voltadas para a formação de professores.

Em 2014, havia um conjunto de 26 programas governamentais implementados pelo MEC voltados à formação inicial e continuada de professores ${ }^{7}$. Desse total de programas ligados à formação docente, apenas cinco são específicos para formação inicial, e outros seis voltam-se tanto para a formação inicial como para a continuada. Do total desses programas, 81\% (ou 21 do total de 26 programas), foram instituídos no período entre 2003 e 2014. Os outros 19\% dos programas foram instituídos entre 1951 (ano de criação da Coordenação de Aperfeiçoamento de Pessoal de Nível Superior [Capes]) e 2000.

É diante desse conjunto de políticas e de demandas de formação de professores que o Pibid se insere. O programa é resultado de uma ação conjunta entre o MEC, por intermédio da Secretaria de Educação Superior (SESu), a Capes $^{8}$, e o Fundo Nacional de Desenvolvimento da Educação (FNDE), e instituído em dezembro de 2007, na gestão do presidente Luis Inácio Lula da Silva e do Ministro da Educação Fernando Haddad, ambos do Partido dos Trabalhadores. Apesar do edital de lançamento do programa ter sido publicado em dezembro de 2007, suas atividades somente iniciaram nos primeiros meses de 2009. O programa apresenta como objetivo formal unir as secretarias estaduais e municipais de

\footnotetext{
7 Estes programas contemplam cinco subáreas: dez na Educação Básica; quatro na Educação Profissional e Tecnológica; sete de Educação Superior; um de Alfabetização e Educação de Jovens e Adultos; quatro na área Diversidade. Recuperado de http:/ / portal.mec.gov.br/index.php?option=com_content\&view=article\&id=15944:programas-do-mecvoltados-a-formacao-de-professores

${ }^{8}$ Em 2007, foi criada a Diretoria de Educação Básica (DEB) da Capes, que conferiu à Capes as atribuições de induzir e fomentar a formação inicial e continuada de profissionais da educação básica e estimular a valorização do magistério. Em 2012, o nome da diretoria foi alterado para Diretoria de Formação de Professores da Educação Básica, mantendo-se a sigla DEB. Com isso, a Capes passa a induzir e fomentar a formação inicial e continuada de professores para o ensino fundamental e médio.
} 


\section{pro-posıções \\ $e$-ISSN 1980-6248}

educação e as universidades públicas a favor da melhoria do desempenho das escolas públicas e o incentivo à carreira do magistério, contribuindo para o aperfeiçoamento da formação de docentes em nível superior (Capes, 2010).

Em sua estrutura original, o Pibid ofertava cinco modalidades de bolsas aos participantes do projeto de cada IES, são elas: os estudantes dos cursos de licenciatura; supervisores (professores da escola pública da educação básica que recebem os licenciandos); coordenadores de área (professores da universidade que coordenam projetos na sua área acadêmica específica); coordenação de área de gestão de processos educacionais (professor da licenciatura que auxilia na gestão do projeto institucional); coordenação institucional (professor da instituição de ensino superior responsável pelo acompanhamento, organização e execução das atividades de iniciação à docência previstas no projeto institucional junto à Capes).

Quanto às escolas parceiras, a recomendação da Capes é que os subprojetos sejam desenvolvidos naquelas que "tenham obtido Índice de Desenvolvimento da Educação Básica (Ideb) abaixo da média nacional e naquelas que tenham experiências bem-sucedidas de ensino e aprendizagem, a fim de apreender as diferentes realidades e necessidades da educação básica e de contribuir para a elevação do Ideb, compreendendo-o nos seus aspectos descritivos, limites e possibilidades" (Capes, 2013, p. 4). Tal indicação se relaciona com um dos objetivos do programa, que é a melhoria da qualidade da educação básica pública brasileira, entendida pelas políticas educacionais como a elevação do Ideb.

As atividades do programa nas escolas e universidades iniciaram em 2009 com 3.088 bolsistas e 43 instituições federais de ensino superior. Em 2014, o número de IES participantes do programa era de 284, com 313 projetos, contabilizando 2.997 subprojetos e 855 campi, envolvendo cerca de 4 mil escolas públicas de educação básica distribuídas pelas cinco regiões do país. Quanto às bolsas concedidas, em 2014 o programa disponibilizava 72.845 bolsas para estudantes de graduação - de um total de 90.254 bolsas -, nas diversas áreas do conhecimento, caracterizando-se até então como política em plena expansão: em 2011 eram 21.598 alunos de licenciatura bolsistas do Pibid'. Em relação ao financiamento, o Pibid contribuiu para preencher, ainda que parcialmente, uma lacuna histórica nas licenciaturas e na formação de professores. Até a sua promulgação havia apenas um programa, além das

\footnotetext{
${ }_{9}^{9}$ Dados recuperados em 06 janeiro, 2016, de http://www.capes.gov.br/educacao-basica/capespibid/relatorios-edados
} 


\section{pro.posıções \\ $e$-ISSN 1980-6248}

http://dx.doi.org/10.1590/1980-6248-2018-0096

bolsas estudantis, destinado às licenciaturas de universidades públicas, o Prodocência, no âmbito da SESu (Freitas, 2007).

A ampliação do programa não foi apenas financeira, em seus primeiros anos, também o foi nas áreas de abrangência. O programa nasce da intenção de incentivar a formação de professores nas áreas mais carentes de docentes: ciências naturais e matemática. Por isso, em seu primeiro edital de dezembro de 2007 , foram priorizados os projetos voltados à formação de docentes para atuar nas áreas do conhecimento em física, química, matemática, biologia, ciências e, de forma complementar, em letras (língua portuguesa), educação musical e artística, e demais licenciaturas.

Essas mesmas áreas prioritárias foram mantidas nos editais de 2009 e 2010, havendo o acréscimo de outras licenciaturas. No edital referente ao ano de 2011, o Pibid deixa de apresentar áreas prioritárias e volta-se para a educação básica como um todo, ficando para cada instituição participante a definição dos níveis a serem atendidos e as áreas prioritárias, verificada a necessidade educacional e social do local ou da região.

Em 2010, é implementado o Pibid Diversidade, com o objetivo de aperfeiçoamento da formação inicial de professores para alunos matriculados em cursos de licenciatura para educação do campo e licenciatura para a educação indígena, no âmbito dos programas Procampo e Prolind, respectivamente, para que desenvolvessem atividades didáticopedagógicas em escolas de educação básica do campo e indígenas (incluídas as escolas quilombolas, extrativistas e ribeirinhas).

Outra alteração ao longo das resoluções referentes ao programa diz respeito às instituições de ensino superior participantes, uma vez que, inicialmente, o Pibid atendia apenas instituições federais de ensino superior. Progressivamente, inclui as universidades públicas estaduais em 2009 e instituições públicas municipais de educação superior e de universidades e centros universitários filantrópicos, confessionais e comunitários, sem fins lucrativos, em 2010. Em 2013, com a promulgação de uma nova portaria a regulamentar a estrutura do programa, as instituições privadas com fins lucrativos que atendem licenciandos do ProUni são também possibilitadas de serem contempladas por essa política. As instituições privadas com e sem fins lucrativos vão ganhando espaço no desenvolvimento do Pibid, autorizadas a participar do programa a partir de 2013; em 2014, essas instituições recebem 18\% das concessões do programa e representam $47 \%$ das IES parceiras. 


\section{pro.posıções \\ $e$-ISSN 1980-6248}

http://dx.doi.org/10.1590/1980-6248-2018-0096

Com a adesão crescente ao programa e o sucesso com que foi recebido na universidade e na escola, houve esforço por parte dos sujeitos que dele participam na tentativa de instituí-lo como política pública para formação docente. O primeiro marco nessa direção é o Decreto $\mathrm{n}^{\circ}$ 7.219, de 24 de junho de 2010, que dispõe sobre o Pibid e dá outras providências, seguido pela inclusão do programa na Lei de Diretrizes e Base nº 9.394/96, com a alteração proposta por meio da Lei no 12.796 (2013), que no artigo 62 incentiva a "formação de profissionais do magistério para atuar na educação básica pública mediante programa institucional de bolsa de iniciação à docência a estudantes matriculados em cursos de licenciatura, de graduação plena, nas instituições de educação superior”. O Plano Nacional de Educação 2014-2024, Lei no 13.005 (2014), na meta 15, estratégia 15.3, institui: "ampliar programa permanente de iniciação à docência a estudantes matriculados em cursos de licenciatura, a fim de aprimorar a formação de profissionais para atuar no magistério da educação básica".

Entretanto, o compromisso político para a efetivação dessas medidas é expresso nos próprios verbos utilizados na alteração da LDB 9.394/96, bem como no PNE 2014-2024; são expressões "fracas", pois indicam que o Pibid deve ser "incentivado" e "aumentado", não havendo obrigatoriedade nem garantia a esse compromisso. O programa fica, portanto, condicionado "à disponibilidade orçamentária e financeira da Capes”, conforme Portaria 96 da Capes (2013).

A partir de 2015, o ajuste fiscal se torna a palavra de ordem do governo federal, numa crise econômica e política que se estende aos anos subsequentes e leva ao contingenciamento de recursos seguido de cortes na verba destinada à educação, impondo restrições crescentes ao financiamento do Pibid. Em 2016 - ano do golpe parlamentar que destitui a presidenta Dilma Rousseff, do Partido dos Trabalhadores -, tem início um processo de diminuição na verba de custeio e nas bolsas do programa, que culmina com sua reestruturação, em 2018, quando o programa tem os recursos divididos com a recém-instituída residência pedagógica. Essas alterações são prescritas com o encerramento dos editais anteriores do Pibid e a promulgação do Edital Capes n $n^{\circ}$ 7/2018. É notória, nesse contexto, a força que a organização interna dos bolsistas Pibid assumiu na manutenção do programa, juntamente ao Fórum Nacional dos Coordenadores Institucionais do Pibid (Forpibid). Essa mobilização foi fundamental na disputa pela hegemonia e pela manutenção dos recursos para o programa até o início de 2018. 


\section{pro.posições \\ $e$-ISSN 1980-6248}

http://dx.doi.org/10.1590/1980-6248-2018-0096

\section{Experiências de subprojetos Pibid}

Constitui o campo empírico da pesquisa os processos formativos de quatro subprojetos Pibid vinculados a licenciaturas da área das ciências da natureza: ciências, ciências biológicas, física e química de uma universidade pública, considerando seus contextos institucionais, epistemológicos, teóricos e práticos, e as políticas para formação docente. Para esse fim, optamos por entrevistas semiestruturadas individuais como recurso metodológico privilegiado para a produção dos dados da pesquisa, pela possibilidade da construção do objeto de estudo a partir da experiência dos entrevistados (Bourdieu, 2011) e, assim, compreender como os subprojetos Pibid investigados têm se desenvolvido na efetivação de suas atividades, como esses sujeitos entendem que essas práticas se estruturam e como contribuem para sua formação como professores. Os cursos são aqueles das ciências da natureza, uma vez que a pesquisadora é formada em ciências biológicas e a realização das entrevistas com professores e alunos dessa área é favorecida, em convergência com Bourdieu (2011), pela importância da familiaridade ao estabelecer o vínculo entre pesquisador e pesquisados.

As entrevistas ${ }^{10}$ foram realizadas ao longo de dois anos de trabalho de campo - entre outubro de 2012 e dezembro de 2014 -, tendo em vista a duração de dois anos de cada edital Pibid, com 14 participantes dos 4 subprojetos Pibid investigados: 5 professores coordenadores, 2 professores supervisores e 7 licenciandos bolsistas. Foram realizadas três entrevista com cada um desses sujeitos: a primeira no início do desenvolvimento do projeto segundo semestre de 2012; a segunda na metade do desenvolvimento do projeto - segundo semestre de 2013; a terceira e última no segundo semestre de 2014. Cada entrevista teve duração média de uma hora.

A escolha por essa instituição se deu em razão de ter um projeto Pibid institucional em pleno desenvolvimento desde 2009. Esse projeto descreve como objetivo desenvolver ações nas perspectivas formativa, investigativa, dialógica e interdisciplinar, de modo a "criar meios institucionais para construir e disseminar uma cultura da prática docente [na universidade] que estimulasse os nossos estudantes a optar pela profissão docente e a resistir à banalização e à

\footnotetext{
${ }^{10}$ Indicações de nomes, de lugares e de pessoas foram suprimidos e os nomes dos entrevistados foram alterados a fim de salvaguardar seus anonimatos.
} 


\section{pro.posıções \\ $e$-ISSN 1980-6248}

http://dx.doi.org/10.1590/1980-6248-2018-0096

desvalorização à qual ela esteve submetida”. Essa universidade possuía, em 2014 ${ }^{11}$, um total de 16 subprojetos, contemplando 588 bolsas de Iniciação à Docência, com 47 escolas parceiras sendo que uma mesma escola pode receber mais de um subprojeto -, e 84 professores supervisores.

Para a organização do trabalho desenvolvido nesses subprojetos, há um modelo mais ou menos comum que se repete nos grupos investigados, sendo, inclusive, estimulado pela coordenação institucional, segundo o qual os licenciandos bolsistas devem dedicar 30 horas mensais ao programa (normativa da Capes), divididas em 8 horas semanais. Essa carga horária semanal é cindida em dois momentos: 4 horas para reunião realizada na universidade e 4 horas para as atividades desenvolvidas na escola.

Quanto aos nossos sujeitos, os professores supervisores são concursados, essa é uma das premissas institucionais para que possam participar do programa. Os professores coordenadores são doutores nas suas áreas específicas de formação, e são professores dos departamentos específicos de seus cursos, nenhum deles é vinculado ao setor de educação; todos possuem experiência com docência na educação básica. Nenhum desses professores coordenadores é professor da disciplina de estágio/prática de ensino na licenciatura. Os alunos bolsistas cursavam do primeiro ao último período de seus respectivos cursos e todos afirmaram querer ser professor.

Os sujeitos entrevistados destacam com entusiasmo aspectos positivos a partir de suas próprias vivências, destacando o programa como um evento muito relevante em seus processos formativos. São diversos os aspectos positivos levantados, como a inserção do licenciando-bolsista na escola parceira, a articulação entre teoria e prática, o desenvolvimento de planos de ensino e atividades em colaboração com diferentes sujeitos, a vivência de um tempo que possibilitou a expressão da subjetividade dos entrevistados, a promoção de formação continuada não só do professor da educação básica, como também do professor do ensino superior, a possibilidade de uma bolsa que permitiu a permanência estudantil. Seus dizeres são representativos na medida em que, ao exprimirem as posições específicas de quem os enunciam, também são constitutivos de um dizer comum sobre esse programa. Nas

11 Dados recuperados em
basica/capespibid/relatorios-e-dados 


\section{pro.posıções \\ $e$-ISSN 1980-6248}

palavras da licencianda bolsista de Biologia $\mathrm{LBC}^{12}{ }^{12}$ : "É muito gratificante, foi uma das melhores coisas que aconteceu dentro da universidade para realmente vivenciar a docência. Acho que é isso o Pibid".

De modo geral, esse parece ser um sentimento comum entre aqueles que participam do programa. Tal fato também foi observado nos eventos institucionais do Pibid na universidade que sedia os subprojetos investigados nos quais estavam presentes os demais participantes daquela instituição, como também em congressos e eventos da área da educação e nas publicações sobre o Pibid.

As experiências desses sujeitos e seus respectivos subprojetos serão discutidas a partir de três categorias, estruturadas a partir do referencial teórico supracitado, de modo a enfatizar elementos centrais tanto do Pibid como da licenciatura, bem como a relação entre as duas instâncias formativas, quais sejam: as mediações entre teoria e prática; as mediações entre escola e universidade; as mediações entre Pibid e estágio/disciplinas pedagógicas, apresentadas e analisadas a seguir.

\section{Mediações entre teoria e prática}

Como discutido anteriormente, Schmied-Kowarzik (1988) assevera que a relação entre teoria e prática é a mais fundamental da pedagogia, sendo esse um debate recorrente no campo da formação de professores e fundamental na perspectiva da formação na e pela práxis.

São frequentes as referências feitas ao lugar da teoria e da prática tanto no âmbito do Pibid como no da licenciatura nas entrevistas analisadas. Há, de modo geral, um discurso marcado pela crítica à licenciatura, justificado pela compreensão de que as disciplinas são muito teóricas e o Pibid seria, portanto, a possibilidade da prática na formação, sendo este um dos aspectos mais destacados positivamente no programa.

Há, tanto nos discursos quanto na forma historicamente constituída, a ideia de que a universidade é o lugar da teoria, conformando um senso comum dos discursos sobre a

\footnotetext{
12 A fim de facilitar a comunicação para identificar as falas dos sujeitos, será utilizada a sigla PC para professorcoordenador, PS para professor-supervisor e LB para licenciando-bolsista, acompanhado da inicial do nome do curso - utilizaremos B (biologia) para identificar a licenciatura em ciências biológicas para diferenciar do curso de licenciatura em ciências (C), acrescido de um número (01 a 14) para cada um dos entrevistados. Por exemplo, o sujeito identificado como LBC04 é o licenciando-bolsista do curso de licenciatura em ciências, sujeito 04.
} 


\section{pro.posições \\ $e$-ISSN 1980-6248}

http://dx.doi.org/10.1590/1980-6248-2018-0096

licenciatura, que passa a ser reconhecida como o lugar da teoria e, consequentemente, da falta da prática. Nessa perspectiva, o lugar da prática nos cursos de formação docente é ocupado pelo estágio, porém, de modo desarticulado com as demais disciplinas e realizado, em muitos casos, burocraticamente ao final do curso. Entretanto, apesar desse lugar-comum das entrevistas, elas não são uma narrativa linear: há escapes, lacunas, contradições na compreensão dos sujeitos sobre a relação entre teoria e prática.

Se a universidade é o lugar da teoria, a novidade do Pibid é a relação que possibilita com a prática, como destacou o LBB01: "Isso é a coisa que o Pibid mais me destacou na licenciatura, foi a prática mesmo". Por outro lado, esse mesmo aspecto é discutido em seu oposto pela sua colega de subprojeto LBB02, que aponta para o limite da prática ao enunciar o ponto negativo do trabalho realizado nesse grupo: "Eu acho que devia ter mais cursos, eu sinto falta disso, porque é uma coisa muito prática, prática, prática e a gente reflete sobre os temas da educação e não tem um direcionamento teórico bom".

O licenciando-bolsista do subprojeto de Física LBF05 coloca a teoria em movimento com a prática ao ressaltar a importância da primeira para a compreensão e atuação na realidade. Ainda que a universidade se mantenha como o lugar da teoria nesse discurso, ela não é estática, mas mostra um movimento possível, ainda que hierárquico, entre teoria e prática, da teoria como mediação para a inserção na futura práxis docente.

Com os estudos, com os referenciais teóricos a gente não vai despreparado para a sala de aula como, talvez, se a gente não tivesse essa fundamentação teórica, a gente fosse ter muitas surpresas em sala de aula. Quando a gente tem um referencial teórico, eu acho que, pelo menos para mim, a gente vai mais preparado, a gente vai mais confiante daquilo que a gente quer. Eu acho que é importante também nisso, é mais direcionado o negócio (LBF05).

A licencianda bolsista do subprojeto de Física LBF06 destaca outro aspecto da articulação entre a teoria da universidade e a prática da escola ao adicionar a relação entre o conhecimento das disciplinas de referência ofertadas pelo Departamento de Física e o conhecimento das disciplinas ofertadas pelo setor de educação, que também costumam ser dicotomizados, com as expressões "disciplinas do bacharelado" e "disciplinas da licenciatura", apagando-se, com isso, o fato de que o conhecimento específico da física também é parte da formação do futuro professor. Nesse sentido, o papel do professor-supervisor é enfatizado como sendo o elemento central que realiza a mediação entre essas áreas de conhecimento. 


\section{pro.posições \\ $e$-ISSN 1980-6248}

Essa vinculação do professor-supervisor ao Pibid será explorada a seguir, ao discutirmos as mediações entre escola e universidade.

\section{Mediações entre escola e universidade}

A relação entre escola e universidade é instável, delicada e socialmente construída, envolve atores de diferentes instituições, relações de poder, posições sociais e objetivos diversos. Talvez, por essa complexidade, apresenta-se como um dos aspectos mais frágeis da formação inicial docente, justamente pela dificuldade de constituir relações mais efetivas entre escola e universidade; somam-se, em especial, as dificuldades de acompanhamento - tanto por parte da universidade quanto por parte da escola - em função das condições institucionais de trabalho e da ausência de financiamento próprio para a efetivação de tais atividades. O Pibid, ainda que de modo precário, contribui para superar essa lacuna histórica na formação inicial docente, e reconhece, ao menos em parte, a escola, ela própria, tanto como um local de trabalho como um lugar de formação para o trabalho.

A escola é ressignificada nos subprojetos investigados como futuro local de trabalho dos licenciandos e como atual lugar de investigação e formação. Nessa direção, é significativa a fala do professor-coordenador de química PCQ04:

Ele [professor-supervisor] é a ponte entre a escola e a universidade, que é um fosso enorme. A gente não pode negar que a universidade se encastela, e se encastela mesmo. $\mathrm{O}$ fato de ele estar nesses dois mundos e construir um diálogo é fantástico. ... Se for para dar o mérito de o projeto funcionar bem, tem que creditar mais para os supervisores do que pra mim.

O Pibid contribui, como aponta o professor-coordenador PCQ04, para minimizar o fato de que "a universidade se encastela". Outras expressões com significados semelhantes a esse, como "os intramuros/os muros da universidade", aparecem nas falas de outros sujeitos entrevistados. Os usos dessas expressões manifestam questões interessantes, como a importância de o Pibid residir, em grande parte, na possibilidade de o futuro professor adentrar na escola com acompanhamento e orientação e, assim, atenuar o distanciamento que frequentemente existe entre essas instituições.

Nesse movimento de aproximação entre as duas instituições é relevante que a escola possa assumir sua intencionalidade na formação de professores, de modo que é possível 


\section{pro.posıções \\ $e$-ISSN 1980-6248}

http://dx.doi.org/10.1590/1980-6248-2018-0096

nesses subprojetos a ressignificação do lugar do professor da educação básica nos processos de formação desses licenciandos. O professor-supervisor do subprojeto de física PSF01, ao ser questionado se ele se sente como um formador de professores, responde entusiasmadamente que sim: "Tanto um parceiro que pode ensinar como um parceiro que pode aprender".

Há uma especificidade do trabalho do professor-supervisor para a formação dos futuros professores, geralmente em latência, mas que pode ser realizada quando as condições materiais permitem a emergência dessa potencialidade. Essa posição manifesta uma ruptura na hierarquia tradicionalmente existente entre escola e universidade, recolocando o docente da educação básica para além da posição de reprodutor, reconhecendo sua função como intelectual e, mais, valorizando-o como fundamental para o sucesso do trabalho no âmbito do Pibid.

Freitas (2013), em conferência intitulada “Iniciação à docência: o que temos feito?”, na Universidade Federal da Bahia, discute a dimensão do tempo, fundamental para a organização da vida, destacando o tempo de dedicação ao programa, pois deve-se evitar a intensificação do trabalho do professor-supervisor, que ao receber uma bolsa poderia tê-lo justificado. Além da intensificação do trabalho do professor, há ainda o fato de que os professores que recebem estudantes para a realização do estágio curricular não recebem equivalente contrapartida, gerando uma desigualdade difícil de ser explicada (Freitas, 2013).

\section{Mediações entre Pibid e estágio/disciplinas pedagógicas}

As mediações entre o Pibid e o estágio/disciplinas ofertadas pelo setor de educação/faculdade de educação são centrais na compreensão desse programa. Por um lado, a Capes institucionalmente nega tal relação e reitera que Pibid não é estágio. Por outro, a prática social das atividades desenvolvidas no âmbito desse programa explicitam as similaridades entre Pibid e estágio - e demais disciplinas ofertadas pelo setor de educação, como enunciada pelos sujeitos entrevistados - uma vez que ambos mobilizam os mesmos sujeitos: licenciandos, professores da educação básica e do ensino superior; os mesmos lugares: escola e universidade; e, em muitos casos, os mesmos saberes. 


\section{pro.posıções \\ $e$-ISSN 1980-6248}

http://dx.doi.org/10.1590/1980-6248-2018-0096

Tem-se constituído uma distinção no campo de formação de professores entre dois termos - "estágio" e "iniciação à docência" -, como também nas políticas públicas para a formação de professores recentemente promulgadas, como o Plano Nacional de Educação (2014-2024) e as Diretrizes Curriculares Nacionais para a Formação de Professores (2015), em que esses dois termos têm despontado, deslocando sentidos sobre o que se entende tanto por estágio como o sentido que vai sendo produzido a respeito da iniciação à docência.

Da mesma forma que as mediações entre teoria e prática e entre escola e universidade, as mediações entre o Pibid e o estágio e/ou as disciplinas da graduação revelam um discurso aparente marcado por aspectos negativos dos espaços curriculares da formação docente.

Por outro lado, há falas, ainda que tímidas e pouco estruturadas, que oferecem um contraponto à perspectiva do estágio e das disciplinas ofertadas pelo setor de educação como apenas negativa. Por exemplo, a licencianda-bolsista do subprojeto de física LBF06 relativiza a dualidade entre Pibid e estágio/disciplinas pedagógicas, apresentando-os como dois momentos de um mesmo processo pedagógico:

O curso de licenciatura é para formar professores, e aí no Pibid você já está lidando com situações da escola, você vai vivenciar. E algumas coisas que eu estudei aqui nos cursos, nas aulas de educação, aqui nas aulas [das disciplinas ofertadas pelo setor de educação], a gente repete também no Pibid, você vê repetido, você reforça aquilo que você viu, e você complementa as coisas que eu estudei lá, que eu estou estudando aqui. Então, uma coisa está complementando a outra (grifo nosso).

É interessante a percepção dessa licencianda sobre a complementariedade entre Pibid e licenciatura, sendo que tal posição é possível pela mobilização e valorização que ela apresenta pelo curso que frequenta, afirmando mesmo que ela é "a aluna mais feliz do curso", ressaltando a potencialidade da licenciatura.

Concordamos com Pietri e Santos (2015, p. 3), para quem o programa "se apresenta como possibilidade de experimentar práticas formativas que muitas vezes não são possíveis no modelo de formação previsto nas diretrizes curriculares para os cursos de licenciatura". Ou seja, o Pibid encontra suas qualidades justamente nos limites estruturais da licenciatura. 


\section{pro.posıções \\ $e$-ISSN 1980-6248 \\ http://dx.doi.org/10.1590/1980-6248-2018-0096 \\ Pibid e licenciatura - ou, mais especificamente, estágio: que relação é essa?}

A discussão das três categorias de análise apresentadas anteriormente nos leva a uma categoria-síntese dessas mediações, as mediações entre Pibid e licenciatura. Os entrevistados, em diversos momentos das entrevistas, referem-se diretamente a questões sobre o lugar do Pibid e o lugar da licenciatura na formação dos futuros professores. Destarte, pensamos ser necessário questionar tanto a forma como o conteúdo de críticas à licenciatura como "falta prática", "é muito teórica", "estágio tem pouco tempo", "é maçante".

Há um lugar-comum nos discursos sobre o que é a formação inicial de professores. Utilizamos a expressão lugar-comum por entendê-la como aquela naturalizada, portanto, profundamente comprometida com uma ideologia. Desse modo, constitui-se por um já dito socialmente, buscando sempre retornar a um consenso constituído no imaginário social. Por ser um já dito recorrente, não precisa ser explicitado, preenchido pelo discurso socialmente circulante que costuma ser polissêmico. $\mathrm{O}$ uso de um discurso que se baseia nesse lugarcomum sobre a formação de professores é possível porque converge com o senso comum (Gramsci, 1999) ideologicamente construído sobre a educação, que é identificada como problemática, fracassada, precarizada, desconectada da realidade. Esse entendimento tem sido difundindo pela estrutura ideológica hegemônica, buscando constituir um consenso sobre a "crise da educação".

O que esse lugar-comum sobre a licenciatura nos diz tanto sobre o curso como também sobre a própria estrutura desse discurso? É preciso repensar e reelaborar essa crítica, entendendo que a constituição desse lugar-comum não se dá isoladamente no interior do campo de formação de professores, seja como pesquisa, seja como prática. Ao contrário, constitui-se no interior das mais diversas relações do bloco ideológico de seu tempo histórico.

Uma importante questão a ser enfrentada pelo programa diz respeito à relação entre Pibid e licenciatura, mais especificamente, ao estágio. "O Pibid é estágio? Pode substituir o estágio? Seria um tipo de estágio ideal? Na busca pela formação de qualidade, onde as ações do Pibid e a realidade do Estágio curricular vão se encontrar?” (Lima, 2012, p. 244). Montandon (2012) acrescenta outras interessantes questões nessa mesma perspectiva: 


\section{pro.posições \\ $e$-ISSN 1980-6248}

Sobre a consolidação dos projetos e seu acompanhamento pela Capes, como avaliar, por exemplo, se as ações dos coordenadores não são, na verdade, o que já deveria ser feito nos Estágios e Práticas docentes? Ou seja, até que ponto professores recebem bolsas para fazerem o que já fazem, ou o que deveriam fazer: orientar alunos no estágio supervisionado docente? Além disso, como avaliar se um projeto não obrigatório e não curricular está sendo entendido como substituição à realização dos estágios docentes obrigatórios? Até que ponto as experiências com os projetos vão estimular o uso de práticas no currículo ou esvaziar os esforços, pela existência de projeto paralelo? (p. 58).

Concordamos com Lima e Montandon nos questionamentos sobre aquilo que é curricular e, portanto, direito de todos os futuros professores, e aquilo que é complementar, acessível apenas a uma parcela minoritária dos licenciandos. Assim, temos dois termos a permear as licenciaturas e as políticas públicas: estágio e iniciação à docência, sem que haja compreensão quanto às definições e aos limites de cada um. Fica, ainda sem resposta, a questão: o que é a iniciação à docência?

Mesmo que aparentemente semelhantes, Pibid e estágio curricular pertencem a campos de poder com estrutura, funcionamento e condições objetivas diferentes, como bem define Lima (2012). O estágio supervisionado é um componente curricular obrigatório para as licenciaturas, enquanto o Pibid é um programa regulamentado e com financiamento específico fomentado pela Capes e que atende a um grupo restrito de alunos selecionados em cada IES participante. Estágio e Pibid estão separados burocrática e politicamente por normatizações e financiamentos diferenciados. Já a diferenciação pedagógica nos parece mais complexa, se não impossível, de ser realizada.

Assim como o estágio e as práticas de ensino desenvolvidas de forma precarizada agridem a boa qualidade da formação docente, se o Pibid permanecer como privilégio de poucos - uma vez que o programa no período em que financiou maior número de bolsas atendeu apenas $5,38 \%{ }^{13}$ dos alunos de licenciatura -, pode contribuir para aprofundar a distância que separa os alunos em formação (futuros professores que deveriam ser titulados pela universidade pública e de qualidade para todos) e, assim, criar diferentes grupos de licenciandos dentro de uma mesma instituição, para além das diferenças interinstitucionais (Lima, 2012).

\footnotetext{
${ }^{13}$ Segundo os dados do Pibid publicados pela Capes, havia em 2015 um total de 72.845 bolsas de iniciação à docência em vigência. Os dados do Censo 2013 informa que há 1.353.614 matrículas em licenciatura. Ou seja, o Pibid atinge 5,38\% dos licenciandos. Dados recuperados em 6 janeiro, 2015, de https://www.capes.gov.br/educacao-basica/capespibid e http://portal.inep.gov.br/visualizar//asset_publisher/6AhJ/content/matriculas-no-ensino-superior-crescem-3-

8 ? redirect $=$ http $\% 3 \mathrm{a} \% 2 \mathrm{f} \% 2 \mathrm{fportal}$.inep.gov.br $\% 2 \mathrm{f}$
} 


\section{pro.posições \\ $e$-ISSN 1980-6248}

http://dx.doi.org/10.1590/1980-6248-2018-0096

Deve-se assumir um esgotamento das formas historicamente adotadas para responder à formação dos professores diante do crescimento quantitativo da educação básica e dos processos de diferenciação da oferta da educação, de modo que, como afirma Marin (2015, p. 60), "a formação de professores sempre esteve perpassada por questões de desigualdades e sua manutenção na sociedade brasileira”. O fato de criar-se diferentes percursos no interior de um mesmo curso, mas sem ofertar essa possibilidade para todos os alunos, produz hierarquias no processo, colocando dilemas a serem enfrentados por professores e alunos. Poderíamos nos perguntar se o Pibid, ao atingir apenas uma pequena parcela do total de licenciandos, seria mais um mecanismo de diferenciação da oferta educativa.

Ao atribuir a prerrogativa de articulação entre escola e universidade, de valorização da formação de professores para o Pibid e com o relativo sucesso da proposta, temos como uma das consequências o silenciamento dos estágios e das próprias licenciaturas nas discussões sobre formação de professores. A parte é elevada ao todo, e a totalidade é desfocada.

Nesse contexto, não obstante o Pibid seja reconhecido por seus aspectos positivos, tal construção é possível sobretudo com a caracterização negativa dos cursos de formação inicial de professores. Em outras palavras, o sucesso do Pibid só se realiza devido ao fracasso histórico da licenciatura.

Defendemos, portanto, que o estágio seja componente curricular e eixo central nos cursos de formação de professores, organicamente articulado ao PPP do curso e às escolas parceiras com que se vincula. Como afirmam Pimenta e Lima (2004, p. 29), “[c]onsiderar o estágio como campo de conhecimento significa atribuir-lhe um estatuto epistemológico que supere sua tradicional redução à atividade prática instrumental”. Nessa direção, a pesquisa em educação, assim como as práticas de incontáveis professores formadores em todo o Brasil, vem construindo conhecimento e experiências de formação docente na e pela práxis. Entretanto, a esse conhecimento e a essas experiências não têm sido oportunizadas condições para ganharem escala e se tornarem realidade efetiva da totalidade dos cursos de formação de professores.

Desse modo, políticas como o Pibid podem contribuir a fim de ampliar o acúmulo de experiências formativas que superem aquela formação burocratizada e contribuir para a produção de conhecimento no campo da formação docente. Ademais, é preciso ter clareza sobre a inserção contraditória desse programa no projeto hegemônico de mercantilização da 


\section{pro.posıções \\ e-ISSN 1980-6248}

educação, não tendo senão caráter de concessão. Por isso, da mesma maneira como é instituído, pode ser retirado. A atual crise econômica e política, que levou a um robusto corte e reestruturação do Pibid, evidencia as prioridades do atual governo, de modo que o programa vive momentos de incerteza, instabilidade e corre o risco de descontinuidade, conhecido fantasma das políticas educacionais.

Não se pode jamais perder de horizonte que, apesar das imensas dificuldades diariamente vivenciadas na educação pública, há um número expressivo de jovens que ainda hoje escolhem ser professores e cursam licenciaturas. Os dados que emergem das entrevistas realizadas nesta pesquisa evidenciam que não só há disposição para ser professor, como também essa escolha é profundamente carregada por um compromisso social, uma vez que é deliberadamente feita pela possibilidade de intervenção na realidade que a profissão docente possibilita. Ou seja, há disposição da juventude e das trabalhadoras e trabalhadores da educação para a realização da educação pública. Além da formação inicial e continuada dos professores, é preciso investir nas condições de trabalho, salário e carreira, sem citar a negligenciada assistência estudantil. Para tanto, essas políticas só podem ser efetivadas com financiamento adequado à educação pública e estatal, que, como sabemos, só será realizada com mobilização social e luta.

\section{Referências}

Bourdieu, P. (dir.) (2011). A miséria do mundo, 8 a ed. (M. S. S. Azevedo et al., Trad.) Petrópolis: Vozes, 2011. (Obra original publicada em 1993).

Contreras, J. (2002). A autonomia de professores. (S. T. Valenzuela, Trad.). São Paulo: Cortez. (Obra original publicada em 1997).

Coordenação de Aperfeiçoamento de Pessoal de Nível Superior. (2010). Decreto n 7.219, de 24 de junho de 2010. (2010). Dispõe sobre o Programa Institucional de Bolsa de Iniciação à Docência - Pibid e dá outras providências. Brasília, 2010.

Coordenação de Aperfeiçoamento de Pessoal de Nível Superior. (2013). Portaria nº 096, de 18 de julho de 2013. Aperfeiçoa e atualizar as normas do Programa Institucional de Bolsa de Iniciação à Docência. Brasília. 2013. 


\section{pro-posıções \\ $e$-ISSN 1980-6248}

Freitas, H. C. L. (2007). A (nova) política de formação de professores: a prioridade postergada. Educaşão \& Sociedade, 28(100), 1203-1230.

Gramsci, A. (1999). Cadernos do cárcere (Vol. 1, C. N. Coutinho, Trad.). Rio de Janeiro: Civilização Brasileira.

Lei $n^{\circ}$ 12.796, de 4 de abril de 2013. (2013). Altera a Lei no 9.394, de 20 de dezembro de 1996, que estabelece as diretrizes e bases da educação nacional, para dispor sobre a formação dos profissionais da educação e dar outras providências. Brasília. 2013. Recuperado de http://www.planalto.gov.br/ccivil_03/_Ato2011-2014/2013/Lei/L12796.htm

Lei no 13.005, de 25 de junbo de 2014. (2014). Aprova o Plano Nacional de Educação - PNE e dá outras providências. Brasília. 2014. Recuperado em 15 março, 2015, de http://www.planalto.gov.br/ccivil_03/_ato2011-2014/2014/lei/113005.htm

Lima, M. S. L. (2012, julho). A prática de ensino, o estágio supervisionado, e o Pibid: perspectivas e diretrizes para os cursos de licenciatura. Anais do Encontro Nacional de Didática e Prática de Ensino, Livro 2, Araraquara: Junqueira, Campinas, SP, BRA, 16.

Lima, M. S. L. (2008). Reflexões sobre o Estágio/Prática de Ensino na formação de professores. Diálogo Educacional, 8(23), 195-205.

Marin, A. J. (2015). Ações políticas de formação inicial de professores - manutenção de desigualdades. In E. Pietri, V. M. Santos, M. C. Utsumi, \& C. V. A. Galian (Org.) A cooperação universidade-escola para a formação inicial de professores: O Pibid na Universidade de São Paulo (2011-2014). São Paulo: Livraria da Física.

Netto, J. P. (2011). Introducão ao estudo do método de Marx. São Paulo: Expressão Popular.

Montandon, M. I. (2012). Políticas públicas para a formação de professores no Brasil: os programas Pibid e Prodocência. Revista da ABEM, 20(28), 47-60.

Pietri, E., \& Santos, V. M. (2015). Apresentação. In E. Pietri, V. M. Santos, M. C. Utsumi; \& C. V. A. Galian (Orgs.) A cooperação universidade-escola para a formação inicial de professores: $O$ Pibid na Universidade de São Paulo (2011-2014). São Paulo: Livraria da Física.

Pimenta, S. G., \& Lima, M. S. L. (2004) Estágio e docência. São Paulo: Cortez.

Schmied-Kowarzik, W. (1988). Pedagogia dialética: de Aristóteles a Paulo Freire (2a ed.). (W. L. Maar, Trad.). São Paulo: Brasiliense. (Obra original publicada em 1974). 


\section{pro.posıções \\ $e$-ISSN 1980-6248}

Vázquez, A. S. (2011). Filosofia da práxis, 2a ed. (M. E. Moya, Trad.). Buenos Aires: Consejo Latinoamericano de Ciencias Sociles - Clacso: São Paulo: Expressão Popular. (Obra original publicada em 1967).

\section{Dados da submissão:}

Submetido à avaliação em 10 de setembro de 2018; revisado em 05 de setembro de 2019; aceito para publicação em 14 de janeiro de 2020.

\section{Autor correspondente:}

Secretaria Municipal de Educação de São Paulo, Rua Borges Lagoa n. 1230, Vila Clementino, São Paulo/SP - CEP: 040380-03. 